\title{
México y el surrealismo: la dimensión etnográfica
}

Inés Ferrero Cándenas Universidad de Guanajuato

Resumen

Este ensayo aborda un aspecto concreto del diálogo entre México y el Surrealismo: su dimensión etnográfica. En este contexto, quisiera explorar la forma en la que las fuentes no occidentales fueron tratadas por los pensadores y artistas vinculados al surrealismo en sus diferentes fases y etapas. Centrándome específicamente en las fuentes mexicanas, reflexionaré sobre como el contacto etnográfico que el surrealismo tuvo con las culturas prehispánicas, condujo o no a una reestructuración crítica de la otredad y del mal llamado primitivismo entre las vanguardias europeas.

Palabras clave: México y surrealismo, diálogo transatlántico, etnografía, arte mexicano, surrealismo etnográfico.

\section{Abstract}

This study explores one specific aspect of the relationship between Mexico and Surrealism: its ethnographic dimension. Within this context, I would like to explore the ways in which non-western sources were treated by artists and thinkers linked to surrealism in its different phases. Focusing particularly in Mexico, I will consider the ways in which anthropological contact with prehispanic cultures led to a critical reconstruction of otherness and the so called primitivism between European avant-garde. 
Keywords: Mexico and Surrealism, Transatlantic dialogue, Mexican Art, Ethnographic Surrealism.

T a presencia de escritores y artistas Hispanoamericanos en la LEuropa de los años treinta y cuarenta, su contacto con las vanguardias y en especial con el surrealismo, se han convertido en objeto de numerosos estudios. Desde la gran exposición surrealista que se llevó a cabo en la Ciudad de México en 1940 hasta hoy día, este vaso comunicante sigue dando de qué hablar. Algunos de los primeros estudios en el área pertenecen a Juan Larrea, quien en 1944 publica El surrealismo entre viejo y nuevo mundo y en 1967, Del Surrealismo a Machu Picchu. Entre otros estudios pioneros se encuentran el libro de Ida Prampolini, El surrealismo y el arte fantástico de México (1969), y el de Luis Mario Schneider, de 1978, México y el Surrealismo. Mucho más recientes, 2003, son los dos volúmenes dedicados a la "transfusión creativa" y a los "visitantes fugaces" en la colección de Artes de México coordinados por Lourdes Andrade. Pero no es tal cual la relación entre México y el Surrealismo el objeto de este ensayo. Quiero decir que es sólo un aspecto muy particular de esta relación el que me interesa explorar. A saber: su dimensión etnográfica. A pesar de la abundancia de material crítico sobre el surrealismo en las Américas, también es justo decir que el aspecto etnográfico no ha sido tan explotado, al menos no en México. Si bien existen estudios recientes en habla hispana que abordan esta vertiente de estudio, como por ejemplo, Más allá de lo real maravilloso: El surrealismo y el Caribe (2006), de María Clara Bernal Bermúdez, los estudios más exhaustivos desde la perspectiva etnográfica pertenecen sin duda a la crítica anglosajona. Entre algunos de los más importantes se podrían mencionar Dilemas de la Cultura (2001), de James Clifford; Surrealism and the Sacred (2003), de Celia Ravnovitch; Surrealism and the Exotic (2003), de Louise Tythacott; el libro de Amy Fass, The anthropolo- 
gical imagination in Latin American literature (1996); el de Anne Birkenmaier, Alejo Carpentier y la cultura del surrealismo en America Latina (2006), y el más reciente, editado por Dawn Ades y Rita Eder, Surrealism in Latin America: Vivísimo muerto (2012).

La ciencia etnográfica y el pensamiento surrealista irrumpieron en el panorama intelectual europeo con pocos ańos de diferencia. La actividad antropológica, al apreciar todo tipo de iniciativa relacionada con la libre expresión de los instintos y al revalorizar lo primigenio, rápidamente captó el interés del grupo surrealista y otros artistas de vanguardia, especialmente en sus descripciones de grupos y sociedades desconocidas por aquel entonces. En 1925, un año después de la publicación del Primer Manifiesto Surrealista, se creó el Instituto de Etnografía de la Sorbonne. El movimiento surrealista apenas estaba en sus inicios, pero ya entonces varios integrantes del grupo inicial de Breton se habían convertido en surrealistas disidentes, incluso opositores. Muchos personajes de la vanguardia mostraron un creciente interés por esta "nueva" ciencia y se adscribieron al colegio de sociología. Marcel Mauss ya tenía entre sus alumnos a gente como Michel Leiris, George Bataille, André Masson y Roger Callois, entre otros. En los años de posguerra, la ciencia etnográfica estaba al servicio de las potencias coloniales; los no europeos eran exterminados o militarizados y la etnografía se convirtió en un elemento importante de esta dominación. Es cierto que prácticamente la totalidad de los artistas que simpatizaron con el surrealismo en su primera etapa rechazaron los imperios coloniales ya casi en fase de descomposición. También es cierto que quisieron poner a prueba la mercantilización del arte y la relación de dominación europea en el ámbito cultural, pero no todos tuvieron en cuenta que, al elevar el papel de las culturas no occidentales, corrían el riesgo de caer en una operación retórica similar a la que querían abolir. La relación de los surrealistas con la etnografía es compleja y lo cierto es que incluirlos a todos en el 
mismo rubro sería caer en generalizaciones infructíferas. Como argumentaré en lo que sigue, mi hipótesis es que algunos sí supieron cómo manejar esta perspectiva y otros simplemente cayeron en una idealización de corte orientalista.

El acercamiento de los artistas de vanguardia a las culturas ancestrales y sus objetos arqueológicos no sólo llamó la atención de críticos de arte o literatura, sino de los antropólogos mismos. James Clifford hermanó ambas disciplinas bajo el nombre de "surrealismo etnográfico" e identificó tres rasgos comunes entre ellas. El primero se refiere a ver la cultura y sus normas como "arreglos artificiales susceptibles de un análisis despegado" (2001: 150). El segundo es una creencia en "el otro" como objeto crucial de investigación moderna, ya sea este "otro" accesible a través de sueños, trances, fetiches o encontrado en las mentalidades ancestrales. Lo relevante de su argumentación es que ambas disciplinas toman como punto de partida un ordenamiento de la realidad europea en crisis donde "el otro" aparece como la posibilidad de apertura a un relativismo cultural. El tercero es que para ambas, la cultura aparece como una realidad en disputa sobre la que existen gran variedad de interpretaciones mediadas por discursos de poder (15053). Clifford equipara la posición transgresora de la etnografía con el espíritu surrealista en tanto que ambos rastrean culturas antiguas con el fin de reordenar sus propios sistemas de clasificación. Le cito: "surrealismo y etnografía comparten un abandono de la distinción entre alta y baja cultura. Ambos se abastecen de una fuente de alternativas no-occidentales y de una actitud participativa de observación irónica entre las jerarquías y los significados de la vida colectiva" (165).

Ahora bien, no creo que todos los surrealistas hayan participado de la misma actitud ante dichas fuentes culturales. No creo que la forma en la que se sirvieron del material etnográfico indicara en todos los casos una apertura al relativismo cultural. Es esta duda 
la que me hace examinar el modo en que estas fuentes fueron tratadas por los diferentes artistas y pensadores relacionados con el surrealismo. Con este propósito, distinguiré dos grandes grupos: ortodoxos y disidentes. Por ortodoxos me refiero a aquellos que se mantuvieron cerca de André Breton y que continuaron colaborando juntos en una serie de revistas, reuniones y exposiciones. Entre ellos podríamos citar a Benjamin Péret, Paul Eluard, René Crevel, Tristan Tzara, Louis Aragon, Ives Tanguy, Man Ray, Marcel Nadeau, Marcel Duchamp y Max Ernst. Por disidentes entiendo a aquellos que ejercieron oposición a las ideas de Breton y su grupo y que, separándose física e ideológicamente de ellos, tuvieron a bien fundar sus propias revistas, exposiciones y escuelas. Me refiero aquí a individuos como George Bataille, Michel Leiris, Antonin Artaud, Joan Miró, César Moro, André Masson, Hans Bellmer, Roger Callois o Robert Desnos.

El "Mapa surrealista del mundo" (1929) puede tomarse como símbolo de la nueva relación que para principios de los años 30 el surrealismo estaba desarrollando con los sistemas de pensamiento occidentales y no occidentales. De autor desconocido, apareció por primera vez en una revista belga llamada Varietés ¿La intención? Presentar una visión alternativa del mundo que rompiera con las expectativas de la burguesía europea. Después de Alaska, cuyo tamaño es totalmente desproporcionado, México y Perú dominan el resto de América, en la que Estados Unidos apenas sí es un punto insignificante. Rusia prácticamente come toda Europa, en la que sólo se resalta París. En consonancia con este dibujo, en el primer Manifiesto Surrealista encontramos la siguiente afirmación:

Incluso más que con el patriotismo — que es un tipo muy común de histeria- con lo que realmente estamos disgustados es con la idea de pertenecer a un país. Este es el más bestial y menos filosófico de todos los conceptos a los que hemos sido sometidos. Dondequiera que la civilización occidental domina, todo contac- 
to humano ha desaparecido, excepto aquel que se hace a través del dinero (53: 1980).

Más que un mapa del mundo y como se desprende de la cita de Breton, lo que aquí está en juego es la creación de un nuevo patrón cultural. Un patrón que involucrase - entre otras cosas - la creencia de que en el mundo no-occidental se originaba un estrato de pensamiento arcaico coalescente con el nuevo estado mental que el grupo surrealista quería experimentar y por lo tanto, del arte que debía producir. Poco a poco, el febril interés por África y Oceanía fue cediendo paso a un creciente hechizo por las culturas hispanoamericanas, en particular por la peruana, la haitiana y la mexicana. En realidad, este interés ya se venía anticipando desde el número 9 de La Révolution Surréaliste (1927), donde se reprodujo el anuncio de una exposición intitulada Ives Tanguy et Objects d'Amerique y que suscitó gran admiración por parte del público francés. En sus viajes por los países hispanoamericanos, Benjamin Peret compila material suficiente para escribir la Antología de los mitos, leyendas y cuentos populares de América (1949), donde afirma - no sin ingenuidad romántica- que el conocimiento europeo puede renovarse a través del entendimiento y exploración de las cosmogonías de las sociedades prehispánicas. Breton también posee numerosas afirmaciones de este estilo. En concreto sobre México dice lo siguiente:

Imperiosamente, México nos convida a esta meditación sobre los fines de la actividad del hombre, con sus pirámides hechas de varias capas de piedras correspondientes a culturas muy distantes, que se han recubierto y oscuramente penetrado unas a otras. Llevo tiempo queriendo visitar este país. Poner a prueba la idea que ya habia yo formulado sobre el tipo de arte que nuestra sociedad y tiempo necesita. Un arte que deliberadamente sacrifique el modelo externo al modelo interno (1980: 58; cursivas mías). 
Mucho antes que Breton, Apollinaire había mostrado interés en México. Remontándose al surgimiento del lenguaje poético vinculado a las inscripciones rupestres, pictogramas e ideogramas cargados de gestualidad y valores "mágicos", trazó analogías entre los caligramas que estaba produciendo por aquel entonces la vanguardia y los lenguajes artísticos prehispánicos. Al ubicar a los artistas occidentales y no-occidentales dentro de un contexto global, Apollinaire buscaba resaltar la deuda del arte moderno con sus precedentes no-occidentales (157). De alguna manera, su trabajo marca el principio de una nueva tendencia orientalista en la vanguardia: promover las formas artísticas de las culturas indígenas como expresiones más "autenticas" y "elevadas" que las de el arte occidental. Después de su contacto con estas tierras, muchos de estos artistas no hicieron más que idealizarlas y elevarlas a una categoría cultural superior. El proyecto de un relativismo cultural se hundía a medida que éstos percibían el potencial que los mitos, rituales, ceremonias, cosmogonías, y la propia concepción de la naturaleza poseían para proveer de nuevos ingredientes a sus expresiones poéticas.

Por otro lado, uno de los primeros textos que documenta la experiencia antropológica de un vanguardista en zona no occidental es África fantasmal, de Michel Leiris. Éste narra sus andanzas personales alrededor de África como parte de la expedición etnográfica de Marcel Griaule entre 1931 y 1933. En el momento en que Leiris escribió este libro, ya era un surrealista disidente. La experiencia de Leiris en África quizás encuentre su mejor contraparte en los viajes mexicanos de Antonin Artaud quien, como resultado de los mismos, narra sus vivencias entre las comunidades indígenas del país en México y viaje al país de los Tarahumaras (1944). Alrededor de esos ańos, pero en el ámbito cinematográfico, Luis Buñuel utiliza el documento etnográfico ligado a su concepción mítica 
del hombre para mostrar algunas de las facetas más oscuras de la realidad mexicana. Podría seguir comentando casos de escritores y artistas aislados, pienso que es a través de las diferentes revistas donde mejor se aprecia el tratamiento de la dimensión etnográfica dentro del surrealismo. La distinción anterior entre surrealistas disidentes y ortodoxos aplica de igual forma para las revistas, pues los miembros que colaboraron en unas y otras obedecen a la misma clasificación. Es decir, que por ortodoxas me refiero a aquellas que estaban de alguna manera u otra bajo la tutela de Breton y por disidentes, aquellas que profesaban una crítica hacia sus ideas. En la primera fase del surrealismo, las ortodoxas eran: La Révolution surréaliste, publicada entre 1924 y 1929; su sucesora, Le Surréalisme au service de la Révolution, que apareció entre 1930 y 1933, y finalmente Minotaure, publicada entre 1933 y 1934 . Aunque en estas revistas abundaba información sobre culturas ancestrales y sus páginas estaban repletas de fotografías e ilustraciones de objetos arqueológicos prehispánicos, africanos o de Oceanía, la relación que mantenían con la etnografía era escasa o nula. Me refiero a que el interés por este tipo de material nunca trascendió el "misterio" que lo encapsulaba. Los rituales descritos, las danzas referidas, la naturaleza exótica y, en fin, todo el mundo material que rodeaba las culturas ancestrales era aquí idealizado, considerado únicamente por su carácter artístico. Ni eran tratadas con rigor etnográfico, ni se les atribuía valor sociológico (Tythacott, 2003: 24). De ninguna manera podemos en este caso sugerir que sus colaboradores se abastecían de las fuentes no-occidentales para mostrar esa "actitud participativa de observación irónica” a la que se refería Clifford, sino para regenerar y abastecer la propia cultura occidental.

George Bataille fue de los primeros en criticar duramente esta postura del surrealismo bretoniano. Su revista disidente Documents, publicada entre 1929 y 1930, desarrolla una teoría del materialismo que restituye la idealización estética surrealista al suelo 
que pisamos, es decir, a lo social. Aunque ampliamente ilustrada, Documents no era una revista de arte propiamente dicha. Fotografías de Bellmer, Desnos, o Boiffard eran utilizadas para iluminar los conceptos concretos de transgresión social que Bataille quería mostrar (Ades, 2006: 91). En Documents, el "primitivismo" fue mostrado en su versión más cruda posible, menos estética, más transgresora. La manera en que el material arqueológico y la información acerca de culturas no occidentales era manejado, sugería que los colaboradores de la revista de Bataille no reducían dichos objetos y culturas a un pasado distante, a un vacío temporal. Tampoco eran considerados estéticamente. Michel Leiris llegó incluso a afirmar que aplicar el término "obra de arte" a estos objetos era una grave equivocación, pues lo único que hacía era restarles su verdadero valor (Ades, 2006: 96). El tratamiento etnográfico de esta información, no sólo sirvió para transgredir los límites de un mundo basado exclusivamente en el arte, sino para realizar un análisis crítico cultural. En este sentido, estaban muy lejos de las imágenes suavizadas y románticas que frecuentaban las páginas de Minotaure y de Le Surréalisme au service de la Révolution (Baker, 2006: 64).

Al combinar el arte con la cultura popular, Documents diseccionaba el mundo arcaico de una manera novedosa e inquietante, a la vez que abandonaba la distinción entre alta y baja cultura. Aquí me atrevería a decir que sí se participaba de esa actitud irónica que trataba de reclasificar las jerarquías y los significados de la vida colectiva (Cfr. Clifford). Igualmente, sus colaboradores señalaban como problemático aquel arte occidental que trataba de imitar de manera superficial las formas y motivos de los objetos arqueológicos americanos o africanos. Bataille, en sus ańos en el colegio de sociología y desde Documents en adelante, buscó algo muy diferente del grupo de Breton a la par que creaba una "alternativa surrealista" al surrealismo: en vez de elevar la cultura primitiva, 
bajó de su pedestal todas aquellas concepciones occidentales de superioridad acerca de las culturas desconocidas. Con esto, también revaloraba las jerarquías del arte y abogaba por una completa libertad de las formas.

Alrededor de 1942, cuando el grupo surrealista estaba escindido por completo, Wolfgaan Paleen comienza en México la revista Dyn. Al igual que Documents en su momento, Dyn se convirtió en una revista disidente del surrealismo Bretoniano. Paalen criticó reciamente los fundamentos filosóficos del surrealismo, especialmente el tratamiento simplista que éste profería de las teorías de Marx y Freud. Lo más relevante para la discusión que aquí me concierne es la fascinación de los fundadores y colaboradores de Dyn por el pasado indígena de las Américas, así como la forma en la que sus artistas mezclaban imaginarios arqueológicos con motivos de objetos indígenas para crear obras de abstracción visual (Leddy y Conwell, 2012: 21). Los artistas de Dyn generaban imágenes que oscilaban entre el documento antropológico y la imagen antirrealista, y al hacerlo mostraban un manejo totalmente diferente de los datos etnográficos que las revistas ortodoxas. Definitivamente en Dyn no encontramos una idealización romántica de la estética, la magia o lo espiritual primitivo, sino un espíritu que estaba mucho más cerca del materialismo de Bataille. La mejor prueba de ello es su número amerindio, una monografía sobre el arte indígena en donde se muestra una perspectiva etnográfica rigurosa (Leddy y Conwell, 2012: 52).

Casi al mismo tiempo, también en 1942, se publicaba en Nueva York la revista $V V V$, dirigida por David Hare y teniendo en su consejo de redacción a André Breton, Marcel Duchamp y Max Ernst. Con propósitos diferentes a los de la mexicana Dyn, la revista de Nueva York mantenía, al igual que Minotaure, La Révolution surréaliste y Le Surréalisme au service de la Révolution, los preceptos de un surrealismo ortodoxo. Dada la escisión y discrepancia de 
ideas que existía entre los artistas que allá por los años veinte habían trabajado juntos, la competencia entre ambas revistas era casi inevitable. Era claro que ya en esta época - finales de los cuarenta y principios de los cincuenta - la revista de Paalen, al igual que en su momento Documents, iba mucho más allá de los preceptos surrealistas bretonianos basados en la disolución de los opuestos. Cuando elementos del arte indígena eran considerados en Dyn, el interés radicaba en su función social y ritual (Leddy y Conwell, 2012: 59). De esta manera evitaban suspender las culturas no occidentales en un vacío atemporal y realmente podían promover reordenar los sistemas de clasificación occidentales. La labor de ambas revistas fue importante en tanto que dieron otro giro al pensamiento surrealista. $\mathrm{O}$ mejor dicho, se concibieron como una alternativa al surrealismo. Este giro, indudablemente marcaba una pauta diferente en tanto al manejo de los datos socio-históricos proporcionados por la antropología y la etnografía. Así, se podría afirmar que en el caso del grupo de disidentes, el contacto con los países americanos, especialmente con México, paulatinamente condujo a una reestructuración crítica de la otredad y del mal llamado primitivismo.

Si bien podría afirmarse que los creadores y colaboradores de Documents y Dyn llegaron a separarse de una visión sacralizada y exótica de lo indígena, no fue así para Breton y los que le seguían en su búsqueda del santo grial. Basta sólo un repaso a los ya citados comentarios de Breton sobre México o a las revistas Minotaure y $V V V$ para darse cuenta de que gran parte de la importancia que tenía el contacto con las comunidades indígenas recaía en el concepto de lo maravilloso. Así visto, México era un mapa de irrealidad donde aún era posible explorar y clasificar la riqueza cultural. Aún en los años cuarenta, el surrealismo ortodoxo seguía tratando de esterilizar la vida de sus trampas materiales y mostraba esa perenne tendencia a representar el ser humano como poseedor de la magia, 
la espiritualidad y el arte. En el fondo, esto era lo que proponía la surrealidad de Breton: un universo milagroso y mágico, pero humano. Es decir, una serie de ideales culturales. En este sentido, no es de extrañar que el grupo ortodoxo encontrara en latitudes mexicanas la fuerza del object trouveé y de lo expresivo del sueño. Que alabaran las culturas no reflexivas e inclinadas hacia una concepción de la historia como destino. Como consecuencia, acabaron por proclamar una nueva mitología de la imaginación basada en la capacidad de los grupos prehispánicos para entrar en contacto con una realidad más "primaria" y "auténtica". En el caso concreto de México, lo más curioso es que esto se produjo en un momento - finales de los años cuarenta principios de los cincuenta- en el que el país estaba en busca de cierta homogeneidad como consecuencia de la necesidad de forjarse una identidad nacional. Contrariamente, el grupo de Breton buscaba heterogeneidad como vía para escapar de la esterilidad de la civilización Europea. Luis Mario Schneider apuntó hace tiempo que lo más irónico de esta relación es el hecho de que cuando los surrealistas, descontentos con la civilización occidental, vinieron a México en busca de las raíces perdidas de una civilización mágica, el gobierno mexicano estaba en proceso de construir un estado-nación basado en el mismo modelo de civilización occidental de los que éstos querían huir (123). La desesperación de Breton y sus amigos por encontrar cualidades representativas que dieran a sus teorías una dimensión universal, no dio lugar a un surrealismo etnográfico como el que refiere Clifford, sino a un nihilismo encubierto.

Aunque es cierto que el interés por las culturas prehispánicas - tanto en el caso ortodoxo como en el disidente- germinó del deseo de atacar la hegemonía colonial y de revitalizar el arte de vanguardia, como se ha visto en lo anterior, algunos abrazaron estas ideas sin darse cuenta de que sólo estaban dando un giro poético a una idea que seguía ocultando la dominación cultural y 
económica de Occidente. A pesar de su rechazo a estos discursos, es obvio que el surrealismo ortodoxo no fue consciente de que al "descubrir" estas culturas, estaban creando una nueva causalidad exótica. Es así que revistas como Minotaure, Le Surréalisme au service de la Révolution o $V W V$ siguieron reproduciendo de forma ingenua estereotipos acerca de las culturas prehispánicas. En su manera de involucrarse con los datos antropológicos, primó el arte sobre lo social, y no se percataron de que la institucionalización de la etnografía para estudiar los grupos humanos, también "reafirma la autoridad de occidente para recolectar, categorizar o incluso canibalizar el capital cultural del otro" (Clifford, 2001: 59). Ahora bien, si la reacción ante lo exótico del grupo surrealista ortodoxo constituyó otra forma de orientalismo, ya se ha comentado como los surrealismos alternos de Bataille, Leiris, Paalen, Moro o Artaud, entre otros, consiguieron luchar contra las jerarquías culturales. En estos casos concretos, creo que sí podemos hablar de un relativismo cultural, de una reordenación de los sistemas de clasificación occidentales y de una problematización de la relación que Europa tenía con la otredad.

\section{Bibliografía}

Ades, Dawn y Bradley, Fiona, 2006, "A playful museum” en Dawn Ades, Simon Baker y Fiona Bradley, Undercover Surrealism: George Bataille and Documents, Cambridge, MIT Press.

Baker, Simon, 2006 "The Appearance of things" en Dawn Ades, Simon Baker y Fiona Bradley, Undercover Surrealism: George Bataille and Documents. Cambridge, MIT Press.

Bretón, André, 1980, Manifiestos del Surrealismo, Barcelona, Guadarrama. Row.

, 1972, Surrealism and Painting, Nueva York, Harper \& 
Clifford, James, 2001, "Sobre el Surrealismo etnográfico” en James Clifford, Dilemas de la Cultura: Antropología, literatura y arte en la perspectiva posmoderna, Barcelona, Gedisa, pp. 149-189. , 2001, "Sobre la autoridad etnográfica" en James Clifford, Dilemas de la Cultura: Antropología, literatura y arte en la perspectiva posmoderna, Barcelona, Gedisa, pp. 39-78.

Dawn, Ades, Rita Eider y Graciela Speranza (eds.), 2012, Surrealism in Latin America: Vivisimo muerto, Los Angeles, Getty Research Institute.

Guillaume, Apollinaire y Marcel Adéma, 1955, Anecdotiques: recueil des chroniques "La vie Anecdotique", París, Gallimard.

Larrea, Juan, 1944, El Surrealismo entre viejo y nuevo mundo, Cuadernos Americanos.

Leddy, Annette y Conwell Donna, 2012, Farewell to Surrealism, The Dyn circle in Mexico, Los Angeles, The Getty Research Institute.

Louise Tythacot, 2003, Surrealism and the Exotic, Nueva York, Routledge.

Nadeau, Maurice, 1972, Historia del Surrealismo, Barcelona, Ariel.

Schneider, Luis Mario, 1978, México y el Surrealismo (1925-1950), México, Arte y Libros.

(Artículo recibido el 13 de junio de 2013; aceptado el 13 de octubre de 2013). 